\title{
Variation of geometrical and physicochemical properties in protein binding pockets and their ligands
}

\author{
Abdullah Kahraman*1, Richard J Morris ${ }^{2}$, Roman A Laskowski ${ }^{1}$ and \\ Janet M Thornton ${ }^{1}$
}

\author{
Address: ${ }^{1}$ European Bioinformatics Institute, Thornton Group, Wellcome Trust Genome Campus, Cambridge, CB10 1SD, UK and ${ }^{2} J o h n$ Innes \\ Centre, Computational Biology Group, Norwich Research Park, Colney Lane, Norwich, NR4 7UH, UK \\ Email: Abdullah Kahraman* - abdullah@ebi.ac.uk \\ * Corresponding author
}

from Third International Society for Computational Biology (ISCB) Student Council Symposium at the Fifteenth Annual International Conference on Intelligent Systems for Molecular Biology (ISMB)

Vienna, Austria. 21 July 2007

Published: 20 November 2007

BMC Bioinformatics 2007, 8(Suppl 8):SI doi:I0.II86/I47I-2I05-8-S8-SI

This abstract is available from: http://www.biomedcentral.com/I47I-2/05/8/S8/S I

(c) 2007 Kahraman et al; licensee BioMed Central Ltd.

\section{Background}

Physicochemical complementarity is commonly believed to be the driving force for molecular binding. The complementarity for example of electrostatic potentials is regarded as the force that draws the ligand from the solvent into the binding site [1]. If this hypothesis is true, the same ligand should encounter complementarity environmental properties in all proteins to which it binds. We have used our recently published ligand and binding pocket matching algorithm [2] to test this common assumption by searching for property distributions that are similar for the same ligand bound to different proteins.

\section{Methods}

The algorithm bases on real spherical harmonic functions, which are applicable to approximate any property function on a unit sphere. These property functions can either be of geometrical or physicochemical nature. For our current analysis we used the shape of binding pockets to test their geometrical similarity and mapped electrostatic, van der Waals and hydrophobicity potentials of the protein on the ligand surface to simulate the physicochemical forces that a ligand may feel in its binding site.

\section{Results}

It was discovered that, of these properties the two that vary least for a given ligand are the binding conformation of the ligand followed by the shape of the binding pocket. Conversely, the same ligand encountered very different electrostatic and van der Waals potential environments in the different proteins to which it is bound. These properties were often found not to be complementary to the ligand's properties, which is in conflict with the general assumption stated above. However, the hydrophobicity of the binding pocket did seem to correlate with the properties of the ligand bound to the protein. Hydrophobic parts of the ligand are often confronted with hydrophobic parts of the protein, giving rise to similar hydrophobicity distributions within different binding pockets binding the same ligand (see Figure 1).

\section{Conclusion}

These results demonstrate that binding sites that bind the same ligand can exhibit a large variation of properties by facing different physicochemical forces within different binding sites. The results urge a re-evaluation of the total contribution of some physicochemical properties to molecular recognition and the factors that drive molecular binding. 

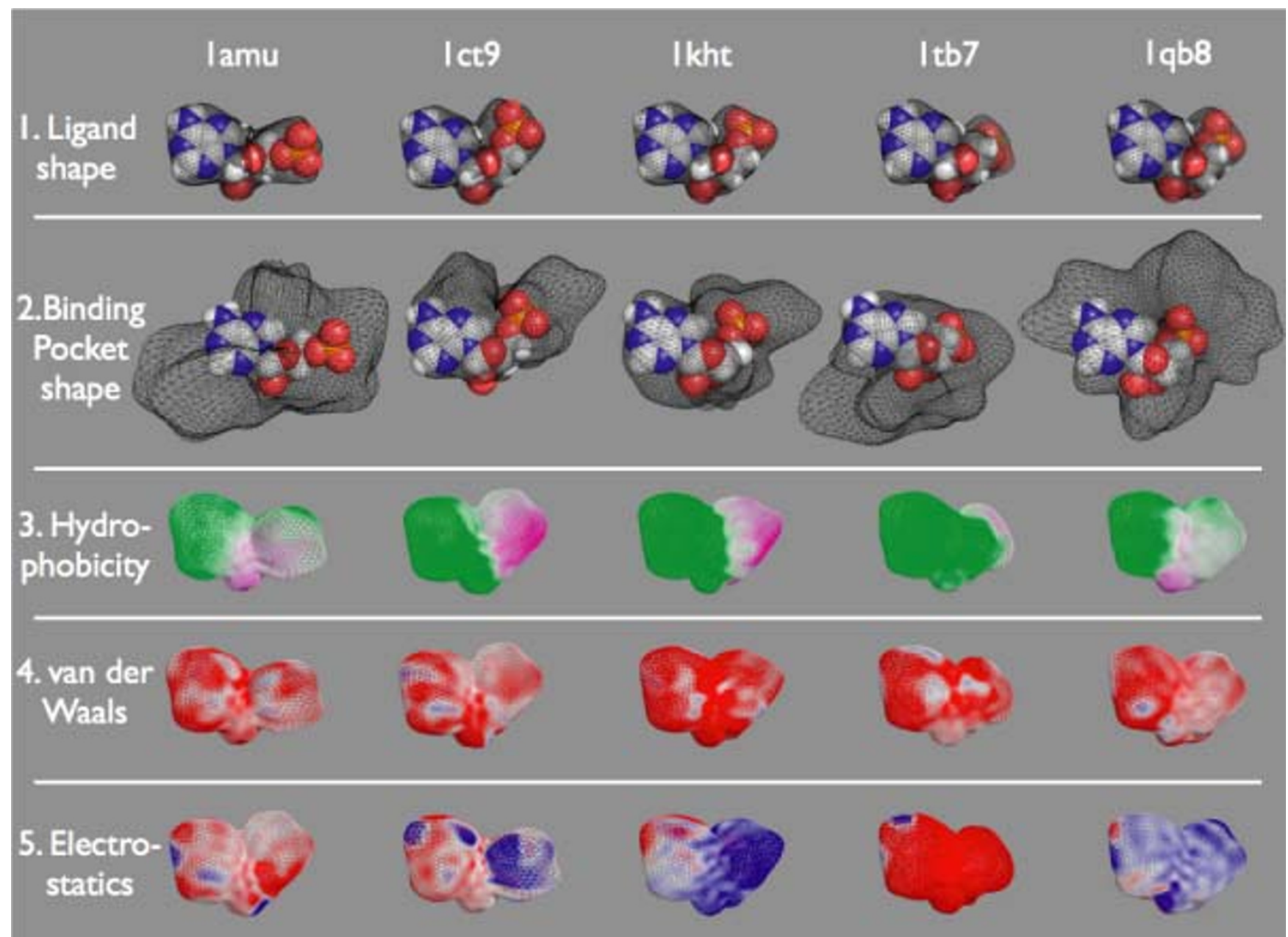

\section{Figure I}

A set of Adenosine-mono-phosphate (AMP) ligands bound to non-homologous binding sites is shown. Each row displays different geometrical and physicochemical properties of the binding site and ligand respectively. From top to bottom are shown the variation of the ligand shape, the binding pocket shape, the hydrophobicity of the protein mapped on the ligand shape, the van der Waals potential and the electrostatic potential both again mapped on the ligand shape. The properties were ordered according to their average degree of similarity among the different binding pockets from highest to lowest from top to bottom. In addition the AMP binding pockets were ranked according to the similarity of their bound ligand to the AMP ligand of the Protein Data Bank [3] structure Iamu [4].

\section{Acknowledgements}

The molecules in the figure were rendered using PyMOL (W.L. DeLano, http://pymol.sourceforge.net/).

\section{References}

I. Livesay DR, Jambeck P, Rojnuckarin A, Subramaniam S: Conservation of electrostatic properties within enzyme families and superfamilies. Biochemistry 2003, 42(1 2):3464-3473.

2. Kahraman A, Morris RJ, Laskowski RA, Thornton JM: Shape variation in protein binding pockets and their ligands. J Mol Biol 2007, 368:283-30I.

3. Berman HM, Westbrook J, Feng Z, Gilliland G, Bhat TN, Weissig H, Shindyalov IN, Bourne PE: The Protein Data Bank. Nucleic Acids Res 2000, 28:235-242.

4. Conti E, Stachelhaus T, Marahiel MA, Brick P: Structural basis for the activation of phenylalanine in the non-ribosomal biosynthesis of gramicidin S. Embo J 1997, 16:4174-4|83.
Publish with Biomed Central and every scientist can read your work free of charge

"BioMed Central will be the most significant development for disseminating the results of biomedical research in our lifetime. "

Sir Paul Nurse, Cancer Research UK

Your research papers will be:

- available free of charge to the entire biomedical community

- peer reviewed and published immediately upon acceptance

- cited in PubMed and archived on PubMed Central

- yours - you keep the copyright
BioMedcentral 